\title{
UDDT with REUSED WATER FLUSH SYSTEM in RURAL and WATER SCARCE AREAS
}

\author{
K Vaishnavi ${ }^{\# 1}$, Kirthana $\mathrm{M}^{\# 2}$, Arun Kumar $\mathrm{K}^{\# 3}$, Abarna $\mathrm{R}^{\# 4}$, Pavithran $\mathrm{P} \mathrm{G}^{\# 5}$ \\ ${ }^{\# 1}$ Department of Civil Engineering, \#2, 3, 4,5 Department of Bio-medical Engineering \\ Sri Sivasubramaniya Nadar College of Engineering \\ Rajiv Gandhi Salai (OMR), Kalavakkam, TamilNadu, India \\ ${ }^{1}$ kvaishnavi029@civil.ssn.edu.in \\ ${ }^{2}$ kirthana15023@bme.ssn.edu.in \\ 3arunkumar15010@bme.ssn.edu.in \\ 4abarna15001@bme.ssn.edu.in \\ 5pavithran15035@bme.ssn.edu.in
}

\begin{abstract}
Sanitation is a term which includes safe disposal of human waste, waste-water management, solid waste management, water supply, control of vectors of diseases, domestic and personal hygiene, and hygiene maintenance in food and housing. Lack of toilets puts India's health and rural people's safety at risk. Open defecation is still in practice in many rural areas resulting in serious social, health, economic and environmental problems. Openly lying human waste enables breeding and transmission of pathogens, which carry diseases and infections. The problem is most acute for children, women, and young girls. Children, especially those under the age of five are most prone to diarrhoea and sometimes even lose their lives to an easily preventable disease. Reusable Water Flush system in Urine-Diverting Dry Toilet (UDDT) is built such that urine is drained from the front area of the toilet and collected in a tank while faeces fall through a large hole in a separate tank. The collected urine is mixed with sand and bacteria to produce bricks like fire clay bricks. The human excreta should be treated with the sun's heat to kill the pathogens and then mix the product with waste materials such as charcoal, dust or sawdust. Faeces have a high fibre content, so when cooled and dried after heat treatment, a hard and solid briquette forms which do not look or smell like human excreta. The briquettes burn just like charcoal but they do not produce any harmful effects to the environment. They can be used to boil water and power turbines to generate electricity. The water used for flushing can be recycled and used again for flushing.
\end{abstract}

Keyword- Bio-bricks, Briquettes, Faeces, Urine-diverting dry toilet.

\section{INTRODUCTION}

The accumulation of untreated human waste in the countryside poses serious health risks and aggravates the problem of already depleting energy sources. Thus, an efficient and renewable waste disposal system is the need of the hour. The separation of waste into solid and liquid waste is implemented by UDDT (Urine-Diverting Dry Toilets).The construction of UDDT toilets require initial investment and lesser maintenance. The faeces waste is used for production of "energy cubes", briquettes - a renewable biofuel. The liquid waste is used as an ingredient in the manufacture of bricks for construction purposes. The water separated from faeces is reused for cleansing purposes by the employment of solid-liquid separator. In this way, there is integrated and efficient use of all types of wastes. Moreover, it is an environmentally acceptable approach and cost effective.

\section{METHODOLOGY}

Building, once completed requires proper maintenance as its starts to deteriorate. Maintaining the building from time to time keeps it in a satisfying condition. Poor and improper building maintenance will cause more damages and costly repair works if left unattended. High rise buildings are at more danger against high velocity of wind force. Building is attacked from all sides from inside and outside. The common problems are settlement, leakage, expansion, and contraction Attack of chemicals can cause corrosion of the surface layer of buildings. This process of deterioration cannot be stopped as it is inexorable but the rate of deterioration can be regulated and the failure can be avoided. 


\section{A. Urine-Diverting Dry toilet}

The accumulation of untreated human waste in the countryside poses serious health risks and aggravates the problem of already depleting energy sources. Thus, an efficient and renewable waste disposal system is the need of the hour. The separation of waste into solid and liquid waste is implemented by UDDT (Urine Dry Diversion Toilets).The construction of UDDT toilets require initial investment and lesser maintenance. The faeces waste is used for production of "energy cubes", briquettes - a renewable biofuel. The liquid waste is used as an ingredient in the manufacture of bricks for construction purposes. The water separated from faeces is reused for cleansing purposes by the employment of solid-liquid separator. In this way, there is integrated and efficient use of all types of wastes. Moreover, it is an environmentally acceptable approach and cost effective.Fig. 1 shows the basic design of Urine-Diverting Dry toilets.
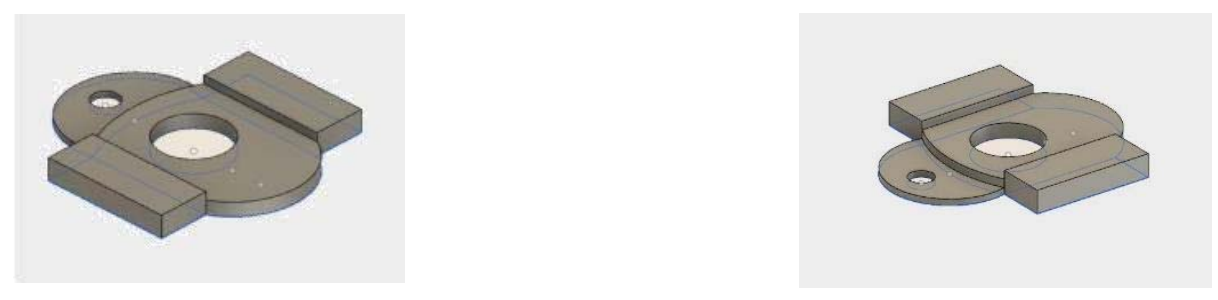

\section{B. Briquettes}

Fig. 1. Urine-diverting dry toilet

Biomass briquettes are biofuel substitute to coal. It has been found that human faeces is used as a solid fuel for heating, cooking and a potential way to address both crises. The elemental composition of chars is pyrolysed at 300,450 and $700{ }^{\circ} \mathrm{C}$. Faecal chars produced at $300{ }^{\circ} \mathrm{C}$ is similar in energy content to wood char and bituminous coal, having a heating value of $25.6 \mathrm{MJ} / \mathrm{Kg}$, while faecal char made at $750{ }^{\circ} \mathrm{C}$ had an energy content of 13.8 $\mathrm{MJ} / \mathrm{Kg}$. Faecal chars made at low temperature were briquetted with molasses/lime and starch binders. These values are comparable to those of commercial charcoal briquettes, making faecal char briquettes a potential substitute that also contributes to the preservation of the environment. The production process also removes harmful pathogens. These briquettes are different from charcoal because they do not have large concentrations of carbonaceous substances. Compared to fossil fuels, the briquettes produce low net total greenhouse gas emission, because the materials used are already a part the carbon cycle. The use of biomass briquettes has been steadily increasing as industries realize the benefits of decreasing pollution.

\section{Bio-Bricks}

The bricks are made in a process called microbial-induced calcite precipitation, or MICP. In a chain of chemical reactions, the microbes on sand are joined together like glue. The resulting brick looks like sandstone, but is as strong as clay-fired brick or even marble. The ingredients include common bacteria and urea, a principal ingredient of human urine. The downside is that microbial-induced calcite precipitation produces vast amounts of ammonia. Microbes convert the ammonia to nitrates, which poisons groundwater. To solve that problem, a system is designed that would capture emissions and recycle them back into the brick-production cycle. Despite the challenges, the bacteria-bricks are a promising solution to a lasting architectural problem. More than 1.3 trillion bricks are manufactured worldwide every year, and many are hand-made in coal-fired ovens. Fig 2 shows the process of production of bio-bricks.

\section{FLUSH WATER REUSE SYSTEM}

The water separated from the liquid solid separator goes into a separate tank. The water enters the tank into the pre-filter. The pre-filter removes any large particulates from the grey water preventing it from entering in to the tank chamber. Once the water enters the tank chamber it is disinfected using the bromine disinfection chamber, which circulates a portion of the water over bromine tablets, disinfecting the water ready for final filtration and use. The tank contains a pump which is used to pump water to the flushing tank. Prior to entering the flushing tank, the water passes through an activated carbon filter, which removes discoloration, particulates, and excess bromine. The process is repeated after each flush. The water separated from the liquid solid separator goes into a separate tank. The water enters the tank into the pre-filter. The pre-filter removes any large particulates from the grey water preventing it from entering in to the tank chamber. Once the water enters the tank chamber it is 
disinfected using the bromine disinfection chamber, which circulates a portion of the water over bromine tablets, disinfecting the water ready for final filtration and use. The tank contains a pump which is used to pump water to the flushing tank. Prior to entering the flushing tank, the water passes through an activated carbon filter, which removes discoloration, particulates, and excess bromine. The process is repeated after each flush.

Fig 3. Shows the Reuse of water flush system.

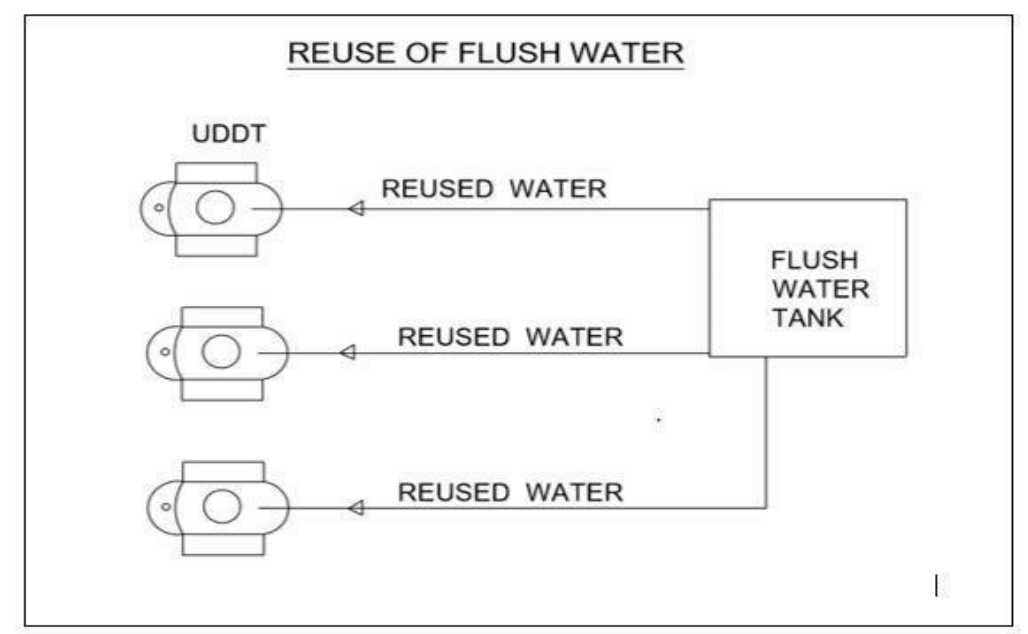

Fig. 3. Reuse of flush water

\section{WORKFLOW}

The purpose includes the following sequence for efficient use of the idea and building clean environment.

- Construction of new UDDT toilets if necessary or suitable modifications in existing toilets for separation of urine and faeces disposal.

- Remove the perception of open defacement and encouragement to use the UDDT toilets.

- Construction of separate collecting tanks under the squatting type UDDT latrines for urine and faeces collection in separate tanks.

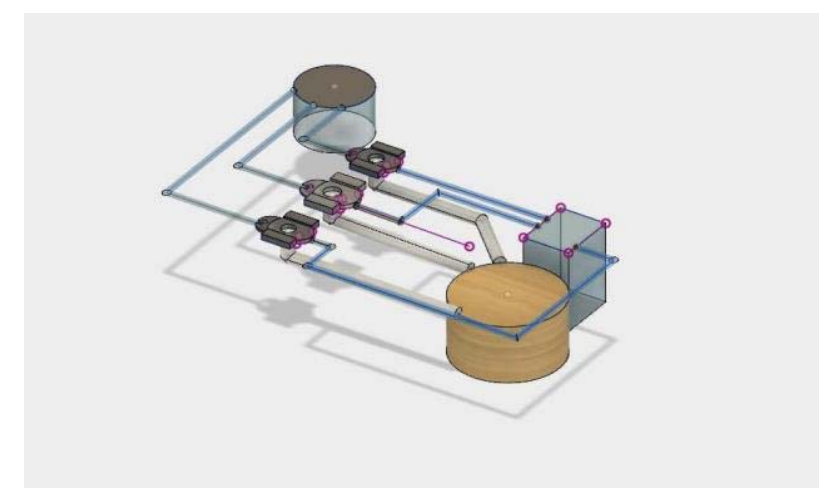

Fig. 4. 3D model of proposed water disposal and system 


\section{DESIGN CONSIDERATIONS}

\section{A. Design criteria for urine collecting tank}

Average density of urine $=1000 \mathrm{~kg} / \mathrm{m}^{3}$

Average amount of urine excreted by a person per day $=1000 \mathrm{ml}$

Total urine excreted by 75 people for 180 days $=13500$ litres

Total mass of urine for 180 days $=13500 \mathrm{~kg}$

Total volume of urine $=13.5 \mathrm{~m}^{3}$

\section{B. Dimensions of urine collecting tank}

Diameter of tank $=3 \mathrm{~m}$

Height of tank $=2 \mathrm{~m}$

Total volume of $\operatorname{tank}=14.13 \mathrm{~m}^{3}$

The designed tank is sufficient to hold urine for a period of 6 months.

\section{Design criteria for faeces pit}

Average density of faeces $=1000 \mathrm{~kg} / \mathrm{m}^{3}$

Average amount of faeces excreted by a person per day $=128 \mathrm{~g}$

Total faeces excreted by 75 people for 365 days $=3504 \mathrm{~kg}$

Total volume of faeces $=3.504 \mathrm{~m}^{3}$

\section{Dimensions of faeces pit}

Diameter of pit $=2 \mathrm{~m}$

Height of pit $=2 \mathrm{~m}$

Total volume of pit $=6.28 \mathrm{~m}^{3}$

The design pit can be emptied after one year or two years depending upon the convenience.

\section{SIGNIFICANCE OF THE PROPOSED SYSTEM}

In the normal toilet system, the urine, faecal and the flush water mix together and go as a waste thereby making them inefficient for further processing. However in our case as we employ a UDDT system which separates all the three waste products, we can make use of these wastes in a productive manner. In case of normal toilet system, the waste remains stagnant leading to accumulation and multiplication of flies due to the odour. This leads to various health issues thereby making the normal people prone to various diseases. However, in case of UDDT on of the major advantage is the absence of odour thereby reducing health hazards related to harmful pathogens and hence forth limiting their transmission. In addition to this, the system is also available for use by diseased people assuring no further health deterioration. This system of UDDT is most welcomed among the common people and the legal frame work also grants its support. In our system, the water which is flushed, mixes with the faeces matter and then gets separated through a solid liquid separation system and is reused for further flushing purposes. This is not possible using a normal toilet system. Using this UDDT system, after separating the faeces and urine, the solid waste is collected in a container and is recycled along with other requisites for making briquettes. Followed by this process, the urine is collected separately and is used in the production of bricks. In case of normal toilets, the transport of the waste to the septic tank via the pipelines may lead to blockage in their path. Here in our system, the collector tank is placed just beneath the toilet sinks and hence the blockage can be prevented as the travelling of the faecal matter is restricted. This reduces the requirement of labours for cleaning the blockage hence forth reducing the cost. In general toilets, lot of water is wasted for the purpose of flushing. However by employing UDDT types of systems, the requirement of water decreases by a large percent thereby making this 
system more witty and feasible in water scarce areas. The faecal matter which is collected for the purpose of briquettes production will be very useful as an alternative fuel in nuclear power plants, for the purpose of cooking, preparation of cooking oil etc. This is a constructive and economical method of recycling the waste. The urine collected in the container which is used for brick production is an economical and conventional method of producing an alternate for the fire clay bricks. Using this technique, the urine will not get wasted and a bio manufactured brick which has the same strength and adherence as a normal brick can be used.

\section{CONCLUSION}

This invention relates to a process of making briquettes for fuel purposes of a low grade of coal. The principal objects of the invention are to provide a process by which the valuable ingredients of the low grade of coal can be formed into briquettes in such a Way that the cost of one step of drying ordinarily employed can be reduced and in which the capacity of the baking oven can be increased to provide a comparatively inexpensive and efficient way of utilizing low grade of coal as mined, and to provide an improved form of briquette. In this process I utilize the well-known process of de-ashing the coal, called the froth flotation process, which is now well known. In case of normal toilets, the transport of the waste to the septic tank via the pipelines may lead to blockage in their path. Here in our system, the collector tank is placed just beneath the toilet sinks and hence the blockage can be prevented as the travelling of the faecal matter is restricted. This reduces the requirement of labours for cleaning the blockage hence forth reducing the cost.

\section{ACKNOWLEDGMENT}

\section{REFERENCES}

[1] Vishakha V. Sakhare, Rahul V. Ralegaonkar, Use of bio-briquette ash for the development of bricks, In Journal of Cleaner Production, Volume 112, Part 1, 2016, Pages 684-689, ISSN 0959-6526, https://doi.org/10.1016/j.jclepro.2015.07.088.

[2] D. Bernardi, J.T. DeJong, B.M. Montoya, B.C. Martinez, Bio-bricks: Biologically cemented sandstone bricks, In Construction and Building Materials, Volume 55, 2014, Pages 462-469, ISSN 0950-0618, https://doi.org/10.1016/j.conbuildmat.2014.01.019.

[3] Mara, Duncan \& Drangert, Jan-Olof \& Nguyen, Viet-Anh \& Tonderski, Andrzej \& Gulyas, Holger \& Tonderski, Karin. (2007). Selection of sustainable sanitation arrangements. Water Policy. 9. . 10.2166/wp.2007.009..

[4] A.Y. Katukiza, M. Ronteltap, C.B. Niwagaba, J.W.A. Foppen, F. Kansiime, P.N.L. Lens, Sustainable sanitation technology options for urban slums, In Biotechnology Advances, Volume 30, Issue 5, 2012, Pages 964-978, ISSN 0734-9750, https://doi.org/10.1016/j.biotechadv.2012.02.007.

[5] R.K. Ihalawatta, K.A.B.N. Kuruppuarachchi, A.K. Kulatunga, Eco-Friendly, Water Saving Sanitation System, In Procedia CIRP, Volume 26, 2015, Pages 786-791, ISSN 2212-8271, https://doi.org/10.1016/j.procir.2014.07.165..

[6] M.G. Montiano, E. Díaz-Faes, C. Barriocanal, Effect of briquette composition and size on the quality of the resulting coke, In Fuel Processing Technology, Volume 148, 2016, Pages 155-162, ISSN 0378-3820, https://doi.org/10.1016/j.fuproc.2016.02.039..

[7] P.Nagala, M.Burt, S.Gonzaga \& A.Bastable, Kenya, "Ecological sanitation in refugee camps, implementing urine diversion dry toilet in dollo ado", 37 ${ }^{\text {th }}$ WEDC international conference, Hanoi Vietnam, 2014.

[8] Cecilia H. Lalander, Geoffrey B. Hill, Björn Vinnerås, Hygienic quality of faeces treated in urine diverting vermicomposting toilets, In Waste Management, Volume 33, Issue 11, 2013, Pages 2204-2210, ISSN 0956-053X, https://doi.org/10.1016/j.wasman.2013.07.007.

\section{AUTHOR PROFILE}

K Vaishnavi, is a third year student at the department of Civil Engineering, SSN College of Engineering, Kalavakkam.

Kirthana M, is a third year student at the department of Biomedical Engineering, SSN College of Engineering, Kalavakkam.

Arun Kumar K, is a third year student at the department of Biomedical Engineering, SSN College of Engineering, Kalavakkam.

Abarna R, is a third year student at the department of Biomedical Engineering, SSN College of Engineering, Kalavakkam.

Pavithran P G, is a third year student at the department of Biomedical Engineering, SSN College of Engineering, Kalavakkam. 